\title{
Demographic Parameters and Distribution of Educational Institutions among the Three Senatorial Districts in Lagos State
}

\author{
Olaniyonu, S. O. A. (Ph.D.) \\ Lagos State University, Faculty of Education, \\ Department of Educational Management, Ojo \\ Gbenu, J. P. (Ph.D.) \\ Lagos State University, Faculty of Education, \\ Department of Educational Management, Ojo
}

Lawal, R. O.

Micheal Otedola College of Education Noforija, Epe

\begin{abstract}
The purpose of the study was to find out the extent to which fairness and equity existed in the distribution of educational institutions among the three Senatorial Districts in Lagos State namely Lagos East, Lagos West and Lagos Central, using demographic parameters of population size, density and land mass. To determine this, two research questions were raised. Using the population of the study as sample, purposively, and adopting expost facto research design, the sample size was the three Senatorial Districts in Lagos State made up of the twenty local governments in the state. Using descriptive analysis of Figures and Tables, findings indicated the presence of fairness and equity in the distribution of educational institutions among the three Senatorial Districts in the State. Some of the recommendations include the need to redistribute the constituent parts of each Senatorial District possibly in favour of Lagos Central to allow for increase in population and consequently increase in school location and the need to use land mass as a factor considering future expansion, given the fact that Lagos East has the largest land mass but second in terms of the distribution of educational institutions.
\end{abstract}

Keywords : demographic parameters, Lagos Senatorial Districts, educational institutions

\section{INTRODUCTION}

One of the greatest challenges facing effective educational planning is unreliable statistics and information. Many educational planning steps embarked upon in developing countries have ended in a fiasco due to this ugly situation. This trend has often forced contemporary planners to be passionate and highly religious about data for planning and the mode of handling same.

In Nigeria, one of the major causes of the failure of the Universal Primary of Education in the Eastern Part of the country in 1957 and in the entire country in 1976 was unreliable data which led to unimaginable explosion in student enrolment leading to insufficient provision of human and nonhuman resources. This situation also manifested itself in the Unity Party of Nigeria (UPN)'s led states in the country between 1979 and 1983 under the civilian administration.

An important issue arising from these scenarios is the necessity to plan with reliable facts irrespective of the level or sector at which such planning is taking place. In education, such facts would present themselves in population (and its dynamics) for the purpose of planning for student enrolments and manpower demand and supply. Not are these data unique and essential to the educational planners, politicians also rely on them to capture votes, who more often than not, concentrate on highly densely populated area to win elections, hence the harp on the slogan of "free education for all" in such areas.

Meanwhile, it should be stated that to increase the quantity and quality of education in a country would require a large dose of teaching-learning facilities: buildings, personnel, books, communication gadgets, laboratories, workshops, among others. A fundamental principle that will assist in this direction as opined by Olatunji (2016) is "equitable access of education to all and sundry, paying a lot of attention to rural areas". 
The study of human population and its dynamics is very important to planners particularly academics and politicians. While the educational planner is interested at the structure of the population for the purpose of projections and provision of facilities, the politician wants to map out political strategies to winning an election. To the educational planner, accessibility to schools by people is of paramount importance. Indeed, the notion of access lends itself to context and purpose. As Baker (1992) points out, "... politicians, academics and the public have defined student access in a number of ways with some definitions having a broader scope than others".

It need be stated that at the heart of demography is human population and its characteristics. Thus demography and successful human-living planning are inseparable. Viewed from another angle, a satisfactory human living would require the application of the principles of equity and fairness, distributing resources according to factors such as population, land mass contributions of areas to national development, among others.

Lagos State, created on the 27th of May, 1967 presently has three senatorial seats of Lagos East, Lagos West and Lagos Central with the population of 17,552,942 by the census of 2006 (though this figure has been contested by the Lagos State government claiming it is somewhere around 20 million) and growing at the rate of $3.2 \%$.

From the foregoing, one thing is certain about demography as the study of human population: it is an essential ingredient for successful planning in any sector of a country and even distribution of resources. Thus, to what extent does the Lagos State government conform to this principle among the three Senatorial Districts of the State in relation to the distribution of educational institutions? Or was the distribution of educational institutions purely political as against the underpinning principle of demography? This situation is therefore worthy of being examined, being the purpose of the study, but first some concepts and terms need be clarified.

\section{THE CONCEPT OF DEMOGRAPHY AND ITS IMPORTANCE}

Demography is the study of human population, a somewhat parallel definition to Fabunmi's (2004) and NOUN's (2011) in the sense that "it is the study of the characteristics of human populations". Such characteristics according to the authors include population size, growth, density, distribution or structure and vital statistics. Considering the processes involved in gathering data and information in relation to these features, it would be convincing enough to refer to the concept as the science of populations.

Demographers seek to understand population dynamics by investigating three main demographic processes: birth, migration, and aging (including death). These processes according to the Population Reference Bureau (2013) "contribute to changes in populations, including how people inhabit the earth, form nations and societies, and develop culture".

As a very general science therefore, it can analyse any kind of dynamic living population, i.e., one that changes over time or space. Beyond size, structure, and distribution of these populations, demography also includes spatial and/or temporal changes in them in response to time, birth, migration, ageing, and death. It would be interesting and acceptable to find out that the Lagos State government is hugely involved in this aspect of planning especially as it involves the provision of education facilities for the inhabitants of the main Senatorial Districts of the State.

The argument of demography being at the heart of planning is not debatable from what has been said so far. Perhaps it is important to buttress this argument with the basic usefulness to which demography can be put as identified by Olaniyonu and Gbenu (2015). This is elaborated below.

a. For adequate planning. Demographic features of any population are of great economic significance because not all the members of the population are productive in the real sense whereas the supply of labour depends very much on the productive sector of the total population. The formulation of economic policies in a country is based on the number of people in that country. In Nigeria for example, population is a major factor in the share of 'national cake'. Demographic planning and projections therefore depend on demographic data availability, giving an idea about population size.

b. It is used to determine the level of development in a nation. This measurement is based on, among other things, the Gross Domestic Product (GDP) and per capita income which are determined with the help of the total population, determining the nation's standard of living in the process if so desired. 
c. It serves as a guide towards programme determination. In education for example, it is essential for educational planners to ascertain the size of the target population so as to be guided on programme size in relation to resource availability.

d. It is a veritable weapon in making accurate forecast. It enables planners to make correct estimates of resources required to implement programmes such as in education. The amount of resources required to implement a programme is determined by the target population or the intended beneficiaries.

e. It reveals the number of people in schools and other dependants. Demographic data give the number of people in schools and colleges and other dependants such as children that are not of school ages and the aged. Once the number is determined, the government can plan for welfare packages.

f. For proper allocation of resources. Planning with faulty data will definitely end in a fiasco, leading to resource wastage in the process.

g. For manpower planning. The attainment of equilibrium between demand for, and supply of manpower, in an economy is a function of reliable data. In addition, demographic analysis provides opportunity to set quantitative targets for the training of high-level manpower in an economy. The available manpower revealed by population census tells the government the size of its recurrent expenses.

h. Demographic data also show the long-term trends of events in a country.

i. It is an important tool in the hands of researchers for national development: health, education, social, politics, etc. many of the research studies carried out are possible through the knowledge of demographic data. Indeed, it can be said that it satisfies human curiosity and thirst for knowledge.

j. It is a basic requirement for school mapping. It assists in determining where schools should be located and where additional facilities are required.

k. It aids the evaluation of human development projects. This situation allows planners to compare performance with standards so as not deviate from set objectives.

1. It is useful in delimitation exercise. Delimitation is the division of a country into constituencies for electoral representation purposes. Such exercise can be successful with accurate data made available.

m. It reveals the population density of a nation. Population concentration or how thickly and sparsely populated an area is can be determined through demographic data.

\section{TheOreTiCal Framework: Demographic Transition TheORY}

The study is anchored on demographic Transition Theory. This is a term that was first used by by Warren S. Thompson (1929), and later on by Frank W. Notestein (1945), referring to a historical process of change which accounts for the trends in births, deaths and population growth that occurred in today's industrialized societies, especially European societies. This process of demographic change began for the most part in the later 18th century. This transition can be broken down into four stages according to the Population Reference Bureau (2013).

\subsection{Stage One: The Pre-Indus trial Stage}

During the pre-industrial stage, societies have high birth and death rates. Because both rates are high, population grows slowly and also tends to be very young: many people are born, but few live very long.

In pre-industrial society, children are an economic benefit to families, reinforcing high birth rates. Children contribute to the household economy by carrying water and firewood, caring for younger siblings, cleaning, cooking, or working in fields. With few educational opportunities, raising children costs little more than feeding them. As they become adults, children become major contributors to the family income and also become the primary form of insurance for adults in old age.

\subsection{Stage Two: The Industrial Revolution}

In stage two, countries begin to industrialize, and death rates drop rapidly. The decline in the death rate is due initially to two factors: improved food production and improved health and sanitation. Food production is improved through more efficient agricultural practices and better transportation 
and food distribution, which collectively prevent death due to starvation and lack of water. Health is improved through medical progress as well as more advanced sanitation methods, especially water supply, seweage, food handling, and general personal hygiene.

As death rates fall, birth rates remain high, resulting in a population explosion. Population growth is not due to increasing fertility, but to decreasing deaths: many people continue to be born, but more of them now live longer. Falling death rates also change the age structure of the population. In stage one, mortality is especially high among children between 5 and 10 years old. The decline in death rates in stage two improves the odds of survival for children. Hence, the age structure of the population becomes increasingly youthful.

In Western Europe, stage two occurred during the 19th century with the Industrial Revolution. Many other developed countries entered stage two during the second half of the 20th century, creating the recent worldwide population explosion.

\subsection{Stage Three: Post-Industrial Revolution}

During the post-industrial stage, birth rates fall, eventually balancing the lower death rates. Falling birth rates coincide with many other social and economic changes, such as better access to contraception, higher wages, urbanization, commercialization of agriculture, a reduction in the value of children's work, and greater parental investment in the education of children. Increasing female literacy and employment lower the uncritical acceptance of childbearing and motherhood as measures of the status of women. Although the correlation between birth rates and these changes is widely observed, it is not certain whether industrialization and higher incomes lead to lower population, or whether lower populations lead to industrialization and higher incomes.

As birth rates fall, the age structure of the population changes again. Families have fewer children to support, decreasing the youth dependency ratio. But as people live longer, the population as a whole grows older, creating a higher rate of old-age dependency. During the period between the decline in youth dependency and rise in old-age dependency, there is a demographic window of opportunity called the demographic dividend: the population has fewer dependents (young and old) and a higher proportion of working-age adults, yielding increased economic growth. This phenomenon can further the correlation between demographic transition and economic development.

\subsection{Stage Four: Stabilization}

During stage four, population growth stabilizes as birth rates fall into line with death rates. In some cases, birth rates may even drop below replacement level, resulting in a shrinking population. Death rates in developed countries may remain consistently low or increase slightly due to lifestyle diseases related to low exercise levels and high obesity and an aging population. As population growth slows, the large generations born during the previous stages put a growing economic burden on the smaller, younger working population. Thus, some countries in stage four may have difficulty funding pensions or other social security measures for retirees.

The original demographic transition model has just four stages, but additional stages have been proposed. Both more-fertile and less-fertile futures have been claimed as a Stage Five.

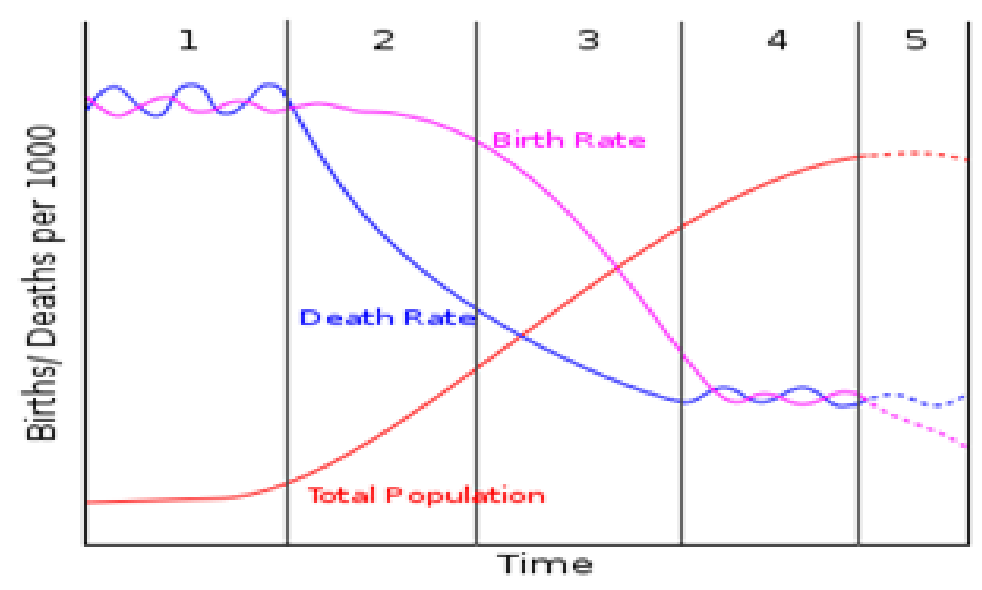

Fig1. A plot of the demographic transition model, including stage 5 
The features of these stages can serve as a guide to Nigerian planners considering Nigeria as a developing country.

\section{The Principles of Efficiency, Equity and Pareto Optimality in Rellation to DISTRIBUTION OF RESOURCES}

The concept of efficiency, though used in education, originated from economics. Both efficiency and equity are at the heart of welfare economics. It is with the aid of these concepts that economists are able to judge whether the existing arrangements about: the methods of production; the types and quantities of goods and services produced and consumed; and the relative share of goods and services going to each household are satisfactory. A satisfactory situation may be said to exist when no rearrangement of the systems of production, consumption and distribution can increase the welfare of one person or group of persons without hurting someone else.

Vilfredo Pareto (1848-1923) was an Italian economist who worked extensively on welfare economics concentrating heavily on efficiency, an approach that was later tagged Pareto Optimality. For a situation to be described as Pareto efficient according to Dwivedi (2004), it must be impossible to increase the production of one good without reducing the production of another, or the consumption of one household without reducing the consumption of another. This situation will result, according to Gbenu (2008), when the following three conditions are satisfied:

a. the given stock of resources must be allocated in the production of goods and services in such a way that no reallocation can increase the output of one good without decreasing the output of any other;

b. the combination of goods and the proportions in which they are produced must be in response to the tastes and preferences of the community - i.e. the goods must be the ones that the community wants;

c. the distribution of goods and services must be in conformity with consumers' preferences, given their tastes and incomes.

With regards to equity, the concept means fairness or justice according to Gbenu (2008). Questions about what is equitable are moral and ethical ones which have their basis in the norms of society. Thus, individual members of a society are bound to have different and conflicting views about what is equitable.

The lesson from here, in relation to the study, is that the distribution of educational institutions among the components of a society should be based on the needs and aspirations of members. Arguments might ensue among these members but it is the prerogative of the government to use necessary arsenals such as the principles of efficiency and equity as well as Pareto Optimality to distribute educational institutions in order to avoid bickering and conflict in the society.

\section{RESEARCH QUESTIONS}

The study was guided by the following research questions

1. What is the trend in the population, land mass and density of the three Senatorial Districts?

2. Does the distribution of educational institutions conform to the trend in 1 above, as a measure of equity and fairness?

\section{MeThodology}

The stepwise procedure for carrying out the study is presented in Table 1 below.

Table1. Tabular Presentation of Methodology

\begin{tabular}{|c|c|}
\hline Items & Description \\
\hline Research Design & Expost facto \\
\hline Population and Sample & $\begin{array}{r}\text { The three Senatorial Districts in Lagos State made of 20 local governments } \\
\text { which also served as the sample for the study purposively. }\end{array}$ \\
\hline Instrument & Primary data from the Lagos State Ministry of Education. \\
\hline Validity and Reliability & $\begin{array}{r}\text { Since the records were given by the State government, they were as sumed to } \\
\text { possess the basic psychometric properties of research instruments. }\end{array}$ \\
\hline Data Analysis & Descriptive statistics of charts and Tables were used for analysis \\
\hline
\end{tabular}


Olaniyonu, S. O. A. et al.

\section{DAta ANALYSiS}

Research question 1

What is the trend in the population, land mass and density of the three Senatorial Districts?

Table2. Population, land mass and density in the three Senatorial Districts of Lagos State

\begin{tabular}{|c|c|c|c|c|}
\hline 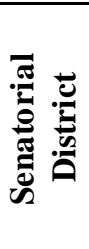 & 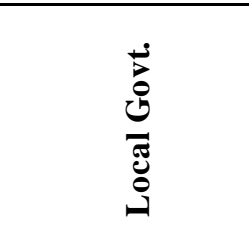 & 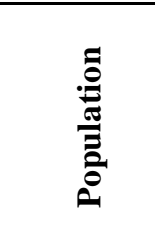 & 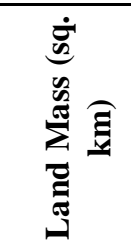 & 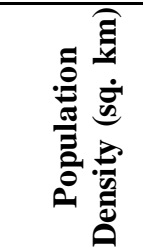 \\
\hline \multirow{7}{*}{ 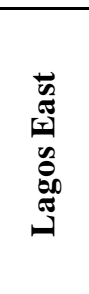 } & Epe & 323634 & 965 & 335.37 \\
\hline & Eti-Osa & 983515 & 299.1 & 3288.25 \\
\hline & Ibeju-Lekki & 99540 & 653 & 152.43 \\
\hline & Ikorodu & 689045 & 345 & 1997.23 \\
\hline & Kosofe & 934614 & 84.4 & 11073.63 \\
\hline & Shomolu & 1025123 & 14.6 & 70213.90 \\
\hline & Total & 4055471 & 2361.1 & 1717.62 \\
\hline \multirow{11}{*}{ 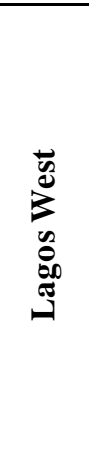 } & Agege & 1033064 & 17 & 60768.47 \\
\hline & Ajeromi/Ifelodun & 1435295 & 13.9 & 103258.63 \\
\hline & Alimosho & 2047026 & 137.8 & 14855.05 \\
\hline & Amuwo/Odofin & 524971 & 179.1 & 2931.16 \\
\hline & Badagry & 380420 & 443 & 858.74 \\
\hline & Ifako/Ijaiye & 744323 & 43 & 17309.84 \\
\hline & Ikeja & 648720 & 49.92 & 12995.19 \\
\hline & Mushin & 1321517 & 14.05 & 94058.15 \\
\hline & Ojo & 941523 & 182 & 5173.20 \\
\hline & Oshodi/Isolo & 1134548 & 41.98 & 27025.92 \\
\hline & Total & 10211407 & 1121.75 & 9103.10 \\
\hline \multirow{5}{*}{ 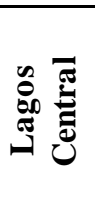 } & Apapa & 522384 & 38.5 & 13568.42 \\
\hline & Lagos/Island & 859849 & 9.26 & 92856.26 \\
\hline & Lagos/Mainland & 629469 & 19.62 & 32083.03 \\
\hline & Surulere & 1274362 & 27.05 & 47111.35 \\
\hline & Total & 3286064 & 94.43 & 34798.94 \\
\hline
\end{tabular}

Source: Lagos State Ministry of Education (2013)

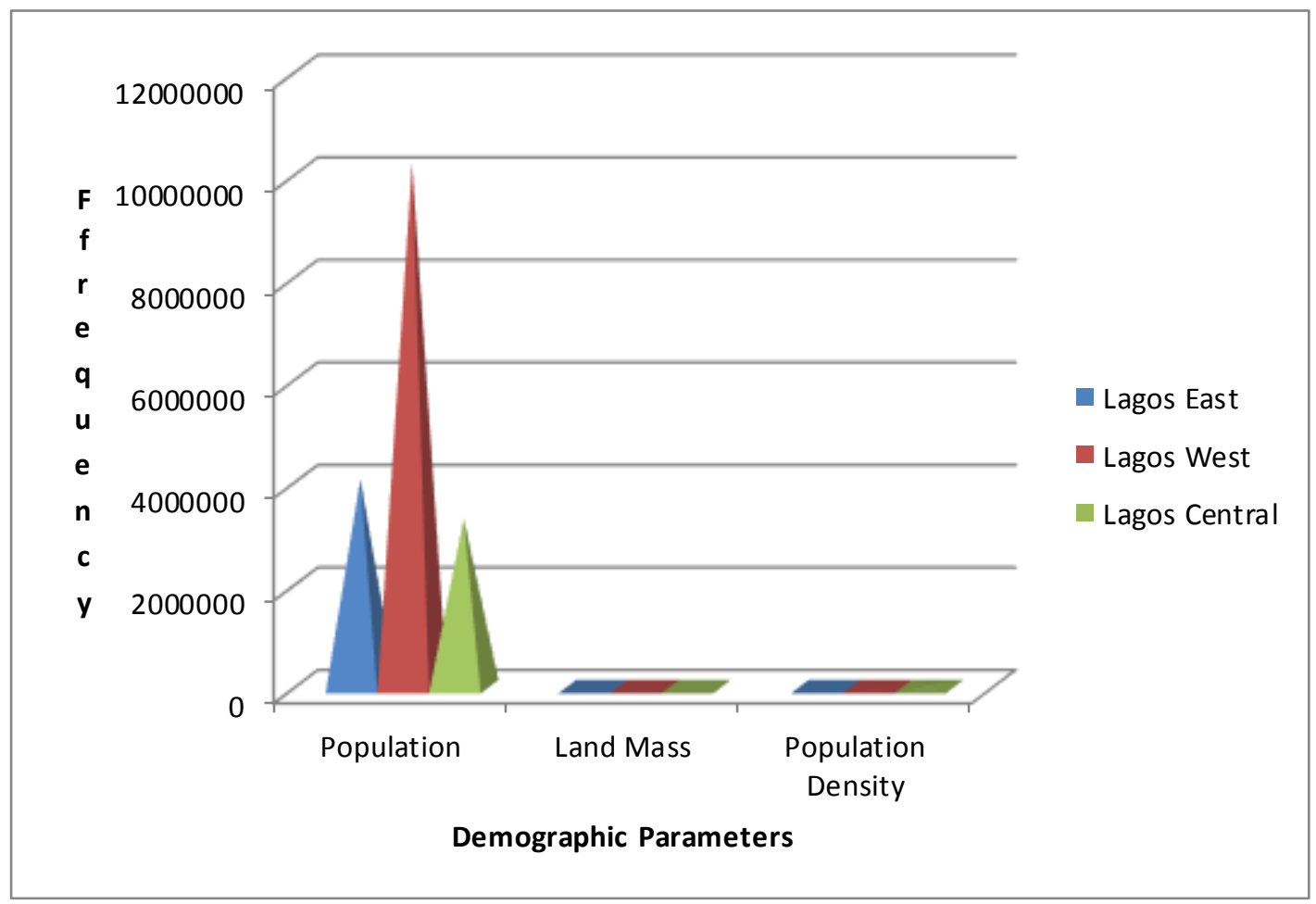

Fig2. Population, land mass and density in Lagos State Senatorial Districts 
Demographic Parameters and Distribution of Educational Institutions among the Three Senatorial Districts in Lagos State

A critical look at Table 2 shows that, Lagos West has the highest number of population, second in land mass and density. Lagos East came second in population, first in land mass and third in density. Lagos Central on its own came third both in population and land mass but highest as far as density is concerned. It seems the pattern in population distribution dictates largely the delineation of the State into Senatorial Districts. For instance, Lagos West has the highest number of local governments of 10 and recorded the highest population in spite of lower land mass and density than Lagos East and Lagos Central respectively. Perhaps, this factor also dictates the distribution of educational institutions in the three Senatorial Districts. Answer to research question 2 will provide a clue to this. Fig. 2 is a display of Table 2 .

Research question 2

Does the distribution of educational institutions conform to the trend in 1 above, as a measure of equity and fairness?

Table3. Distribution of educational institutions by Senatorial District

\begin{tabular}{|c|c|c|c|c|c|}
\hline \multirow{2}{*}{ 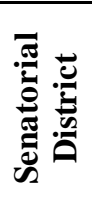 } & \multirow{2}{*}{ 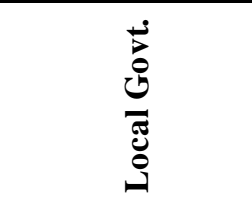 } & \multicolumn{4}{|c|}{ Edu. Inst. (as at 2011/2012) } \\
\hline & & Primary & Secondary & Technical & Tertiary \\
\hline \multirow{7}{*}{ 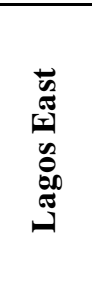 } & Epe & 78 & 51 & 1 & 1 \\
\hline & Eti-Osa & 35 & 37 & 0 & 0 \\
\hline & Ibeju-Lekki & 37 & 18 & 0 & 0 \\
\hline & Ikorodu & 57 & 53 & 1 & 1 \\
\hline & Kosofe & 41 & 28 & 0 & 0 \\
\hline & Shomolu & 48 & 22 & 0 & 0 \\
\hline & Total & 296 & 209 & 2 & 2 \\
\hline \multirow{11}{*}{ 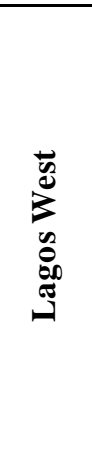 } & Agege & 50 & 16 & 0 & 0 \\
\hline & Ajeromi/Ifelodun & 71 & 39 & 0 & 0 \\
\hline & Alimosho & 74 & 46 & 1 & 0 \\
\hline & Amuwo/Odofin & 43 & 40 & 1 & 0 \\
\hline & Badagry & 53 & 27 & 0 & 0 \\
\hline & Ifako/Ijaiye & 25 & 15 & 0 & 0 \\
\hline & Ikeja & 30 & 24 & 1 & 0 \\
\hline & Mushin & 76 & 31 & 0 & 0 \\
\hline & Ojo & 52 & 31 & 0 & 2 \\
\hline & Oshodi/Isolo & 54 & 47 & 0 & 0 \\
\hline & Total & 528 & 316 & 3 & 2 \\
\hline \multirow{5}{*}{ 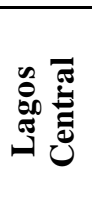 } & Apapa & 24 & 12 & 0 & 0 \\
\hline & Lagos/Island & 32 & 20 & 0 & 0 \\
\hline & Lagos/Mainland & 58 & 23 & 0 & 0 \\
\hline & Surulere & 63 & 57 & 0 & 0 \\
\hline & Total & 177 & 112 & $\mathbf{0}$ & $\mathbf{0}$ \\
\hline
\end{tabular}

Source: Lagos State Ministry of Education (2013)

Again, here it seems the population factor dictated the distribution of educational institutions in the three Senatorial Districts of the State with 528 primary, 316 secondary (both junior and senior), and 3 technical schools as well as 2 higher institutions. This is followed by Lagos East with the higher population having 296 primary, 209 secondary and 2 technical schools with 2 tertiary institutions. Lagos Central with the least population came last in terms of the distribution of educational institutions.

\section{DISCUSSION}

It is not surprising to see population being a strong factor in the distribution of educational institutions in the three Senatorial Districts of Lagos State at the expense of other factors such as land mass and density. This is very common in literature. For example Olatunji (2013) agrees that population study is highly essential for planning because not all the members of the population are productive and the formulation of economic policies in a country is based on the number of people in that country. In a 
related manner, Olaniyonu and Gbenu (2015) submits that population study serves as a guide towards programme determination, for example, it is essential for educational planners to ascertain the size of the target population so as to be guided on programme size in relation to resource availability. Other reasons why population is a strong factor in resource distribution as stated by Campbell (2012) include serving as a veritable weapon in making accurate forecast in education, revealing the number of people in schools and for proper allocation of resources.

\section{Conclusion}

Findings from the study indicated that population size was largely responsible for the distribution of educational institutions among the three Senatorial Districts from the factors considered and the fairness and equity were displayed in the process. Given this background, there should be less bickering and conflicts among the Districts. The signal is that when schools are to be distributed again, the same pattern will be followed, all things being equal. The State government could however give redistribution of the component parts of each Senatorial District a thought because, at present, it is lopsided in favour of Lagos West. This might necessitate giving consideration to other factors beyond population size following the principles of fairness and equity.

\section{RECOMMENDATIONS}

1. There should be redistribution of the constituent parts of each Senatorial District possibly in favour of Lagos Central to allow for increase in population and consequently increase in school location.

2. There is need to use land mass as a factor considering future expansion given the fact that Lagos East has the largest land mass but second in terms of the distribution of educational institutions. Trend of development may shift to that side in future.

3. Given the large population size of Lagos State generally relative to other states in Nigeria, there might be need to increase the supply of schools, especially secondary and technical, to be distributed on the basis of fairness and equity.

\section{REFERENCES}

Baker, M. (1992). Quality and access in the US: what does it mean? Centre for study for higher education, Pennsylvania State University, State College.

Campbell, O. O. (2012). Educational planning, management and school organization. Lagos: Olatunji enterprises.

Dwivedi, D. N. (2004). Principles of economics. New Delhi: Vikas publishing house.

Fabunmi, M. (2004). Perspectives in educational planning. Ibadan: Odun prints and pack.

Gbenu, J. P. (2008). Introduction to economics. Lagos: Micodex Nig. Ltd.

NOUN (2011). Statistical analysis and quantification in educational planning. Lagos: National Open University of Nigeria.

Olaniyonu, S. O. A. and Gbenu, J. P. (2015). Demographic analysis and school mapping: the heartbeats of effective school location. Lagos: Laideb printers.

Olatunji, O. A. (2016). Spatial distribution of educational institutions, student enrolment and staff employment among senatorial districts in Ogun state, Nigeria. Unpublished Ph.D. thesis, Lagos State University, Ojo.

Olatunji, W. (2013). Planning the location of schools: issues in school mapping and records. Ibadan: Joytal printing press.

Population Reference Bureau (2013). World population factsheet. www.pbr.org. Population Reference Bureau. Retrieved 5th August 2015. 